\title{
Pullulan-Stabilized Silver Nanoparticles-Their Synthesis, Characterization and Application as Bactericidal Agents
}

\author{
V. S. Rama Krishna Ganduri ${ }^{1,2}$, Ushakiranmayi Mangamuri ${ }^{3}$, Vijayalakshmi Muvva ${ }^{3}$, Sudhakar Poda $^{2 *}$ \\ ${ }^{1}$ Department of Biotechnology, K L University, Vaddeswaram, Guntur, India ., ${ }^{2}$ Department of Biotechnology, Acharya Nagarjuna University, \\ Nagarjunanagar, Guntur -522510, India. ${ }^{3}$ Department of Botany and Microbiology, Acharya Nagarjuna University, Nagarjunanagar, Guntur -522510, India.
}

\begin{tabular}{|c|c|}
\hline ARTICLE INFO & ABSTRACT \\
\hline Article history: & \multirow{8}{*}{$\begin{array}{l}\text { A rapid method for Pullulan-stabilized silver nanoparticles (PuAgNPs) synthesis has been developed. Different } \\
\text { concentrations of Pullulan and Silver nitrate and effects of reaction time, } \mathrm{pH} \text { was used to investigate the } \\
\text { synthesis of silver nanoparticles. The synthesized Pu-AgNPs were first screened and identified using surface } \\
\text { plasmon peaks of UV-VIS spectroscopy. The research results indicated that the surface plasmon resonance } \\
\text { peaks were observed between } 410-460 \mathrm{~nm} \text { wavelengths in UV-VIS spectroscopy studies. The morphology of } \\
\text { the synthesized AgNPs proved a variation in spherical shape and polydispersed with an average size of } 10-55 \\
\mathrm{~nm} \text {, using TEM. Further, five characteristic peaks confirmed the presence of elemental silver and the crystalline } \\
\text { structure of silver nanoparticles from XRD analysis. From FTIR spectra, stretching vibrations of hydroxyl (O- } \\
\mathrm{H} \text { ), carbonyl }(\mathrm{C}=\mathrm{O}) \text { and } \mathrm{C}=\mathrm{C} \text { stretches exhibits the reduction and stabilization of AgNPs. Further, clear zones of } \\
\text { inhibition (about } 10-25 \mathrm{~mm}) \text { against four bacterial pathogens obtained in the antibacterial studies for the } \\
\text { synthesized PuAgNPs. The experimental results demonstrated that pullulan could be used as reducing and } \\
\text { stabilizing agent for formation of AgNPs and can be used as redoubtable bactericidal agents. }\end{array}$} \\
\hline Received on: 12/03/2016 & \\
\hline Revised on: 14/05/2016 & \\
\hline Accepted on: 11/06/2016 & \\
\hline Available online: $28 / 07 / 2016$ & \\
\hline Key words: & \\
\hline Pu-AgNPs, TEM, XRD, & \\
\hline FTIR, Bactericidal agents. & \\
\hline
\end{tabular}

\section{INTRODUCTION}

Metal-based nanoparticles find tremendous applications in real time biomedical, nutrition and electronic industries. Of these, gold, silver, zinc and copper induced metal nanoparticles gaining much attention because of their widespread usage. Though several physical and chemical routes have been used for synthesis of metal nanoparticles, the use of non-toxic and benign biological materials like microbes, plant extracts, actinomycetes were included in the MNPs preparation (Bankura et al., 2012; Bindhu and Umadevi, 2013; Kalishwaralal et al, 2010; Narayanan and Sakthivel, 2011; Roopan et al., 2013; Wei et al. 2012). Among these, silver metallic nanoparticles are being produced by common chemical reduction methods with

\section{* Corresponding Author}

Sudhakar Poda, Department of Biotechnology, Acharya Nagarjuna University, Nagarjunanagar, Guntur -522510, India.

Email:sudhakarpodha@gmail.com extracellular and intracellular synthesis through eco-friendly, biocompatible methods. In recent times, interest has grown in research groups for using wide variety of chemical and biochemical reducing agents with these metal nanoparticles (Guari et al., 2003; Hebeish et al, 2013; Kora and Arunachalam, 2011; Moura et al, 2012; Stiger et al, 1999).

In the recent times, a new concept referred as 'green' synthesis of silver nanoparticles using polysaccharides excreted by fungi as renewable polymeric substances is used for stabilization of synthesized NPs (Raveendran et al, 2003). The most extensively used biopolymers for the preparation of SNPs include: Chitosan (Hernane et al., 2011; Singaravelu, 2012), Dextran (Bankura et al, 2012, Yang et al., 2012), Gelatin (Paulraj and Seung, 2013, JongWhan, 2014), Sodium alginate (Shilpa Sharma et al., 2012), Albumin (Mariam et al., 2011), etc. Very recently, few researchers reported the usage of fungal exopolysaccharide, Pullulan as both reducing and stabilizing agent (Kavya et al., 2008; Kanmani et al., 2013; Wu et al., 2013; Spatareanu et al., 2014; Coseri et al., 2015). 
Pullulan is a non-ionic and water soluble linear polysaccharide consists of $\alpha-1$, 6-linked maltotriose sugars, secreted by yeast-like fungus named, Aureobasidium pullulans species. Because of impressive biocompatible, non-immunogenic, non-mutagenic, non-carcinogenic and biodegradable properties of pullulan, pullulan stabilized nanoparticles finds applicability in drug carriers, cytotoxic and therapeutic studies. Many attempts were made by several researchers to study the effect of parameters like concentrations of Pullulan and silver nitrate, preparative (photo induced, electrochemical, solvothermal) methodsand temperature on the formation and growth of silver nanoparticles in the particle size of 2-40 $\mathrm{nm}$.

Unfortunately, little work systematically studies the influence of factors such as reaction time and $\mathrm{pH}$ on size and shape of formed NPs for their absorbance and position of surface Plasmon resonance bands.

In the present study, experiments on increased amounts of pullulanat fixed silver nitrate concentration and increased concentrations of silver at fixed Pullulan weight were carried out. The influence of (increased) reaction time and change in $\mathrm{pH}$ was also studied for direct reduction of silver nitrate with Pullulan to produce Pullulan-stabilized AgNPs. The synthesized Pu-AgNPs were characterized by UV-visible spectroscopy Transmission Electron Microscopy (TEM), X-Ray Diffraction (XRD) and Fourier Transform InfraRed (FTIR) spectroscopy. Further, the antibacterial activity of $\mathrm{Pu}$-AgNPs towards bactericidal agents was studied.

\section{MATERIALS AND METHODS}

\section{Materials and Bacterial strains used}

Biopolymer, Pullulan (Kopulan) was purchased from M/s. Kumar Organic Products Ltd. (Bengaluru, India). Silver nitrate $(M W: 169.87 \mathrm{~g} / \mathrm{mol})$ was procured from M/s. Merck Company Ltd. (India). Media components (Luria Bertani Agar, Potato Dextrose Agar) used in this study were obtained from M/s. Hi-Media Chemical Ltd. (India).

Four bacterial strains Bacillus subtilis, Escherichia coli, Serratia marcescens and Staphylococcus aureus were used to test bactericidal effect of synthesized silver nanoparticles. All solutions were prepared using ultra-filtered high pure deionized water.

\section{Synthesis of Pullulan mediated Silver NanoParticles (Pu-} AgNPs)

For the synthesis of Pullulan mediated Silver Nanoparticles, the increasing concentrations of Silver Nitrate (1 $\mathrm{mM}-10 \mathrm{mM}, 12 \mathrm{mM})$ and Pullulan (0.1 \% - $1.0 \% \mathrm{w} / \mathrm{v})$ (as reducing and capping agent), were mixed together to study the formation of Silver Nanoparticles using intense agitation (hotplate magnetic stirrer) and Sono chemical method (with Ultrasonic processor) to optimize the pullulan concentration for $\mathrm{Pu}-\mathrm{AgNP}$ synthesis.In both the methods used for Pu-AgNPs synthesis, transparent colourless reaction mixture containing $\mathrm{AgNO}_{3}+$
Pullulan was turned to the characteristic pale yellowish-brown color (depending on concentration), which confirmed the formation of silver nanoparticles.

Further, the influence of pH (@ 7.0 and 9.2) and reaction time (5 - 45 min.) on synthesis of Pu-AgNPs were also studied to observe variation in the optical properties of the formed nanoparticles.

\section{Characterization of Pu-AgNPs}

The synthesis of pullulan-mediated AgNPs by direct reduction of silver nitrate with Pullulan in aqueous solutions was characterized for Surface Plasmon Resonance (SPR) using single beam microprocessor based scanning Ultraviolet-Visible spectrophotometer (SL-159,Elico Ltd., India) in the range of 300$700 \mathrm{~nm}$

For the meticulous particle size and crystal structure characterization, a High resolution Transmission Electron Microscope (Tecnai-FEI 12, USA), in which a thin sample was irradiated with a sharp high-energy electron beam (in the range of 100- $200 \mathrm{keV}$ ) and TEM images were taken for synthesized $\mathrm{Pu}$ AgNPs. Further, the phase composition and crystal structures of $\mathrm{Pu}$-AgNPs were determined with X-Ray Diffractometer (PHILIPS PAN instrument). In addition, Fourier transform infrared spectroscopy (JASCO FT-IR 460, Daejon, South Korea) was also performed on synthesized $\mathrm{Pu}-\mathrm{AgNPs}$ to study the characteristic vibration frequencies in infra-red range $\left(500-4000 \mathrm{~cm}^{-1}\right)$.

\section{Bactericidal effect of Pu-AgNPs}

The antibacterial activity of the Pu-AgNPs was investigated against four, two gram-positive (Bacillus subtilis and Staphylococcus aureus) and two gram negative (Escherichia coli and Serratia marcescens) bacterial pathogens using the agar well diffusion method.

All these strains were aseptically inoculated into Luria Bertani broth (LBB) and incubated at $37^{\circ} \mathrm{C}$. Wells were made using Agar well borer method prior to spreading and broth $(0.25$ $\mathrm{ml}$ ) from each liquid culture (overnight grown) was spreaded onto Luria Bertani Agar (LBA) plates.10 $\mu \mathrm{L}$ of Pu-AgNPs samples (from different methods) were added in each well of each Petri dish and incubated at $37^{\circ} \mathrm{C}$ for $24 \mathrm{~h}$.Zones (diameter in $\mathrm{mm}$ ) of bacterial growth inhibitions were measured and tabulated the average values of three independent experiments. Distilled water and 5\% Silver Nitrate solutions were used as controls for comparison.

\section{RSEULTS AND DISCUSSION}

\section{UV-visible Spectrophotometer measurements}

Due to excitation of Surface Plasmon Resonance (SPR) band in UV- visible region, the silver nanoparticles exhibit yellowish brown in colour (Burda et al., 2005, Liz-Marzan, 2006). The effect of increasing concentration of Pullulan from $0.1-1.0$ $\%$ (by w/v)in the development of colour change from yellow to Yellowish brown is shown in Fig.1. 


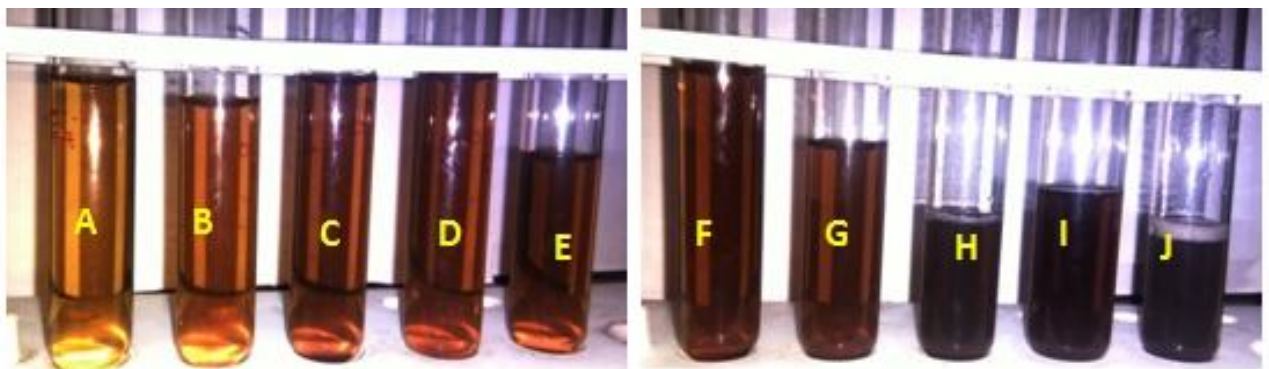

Fig. 1: Development of characteristic yellowish brown color in synthesis of silver nanoparticles in test tubes for increasing concentration (by $\%$ w/v) of Pullulan (A to $\mathrm{J}=0.1$ to1.0\%).
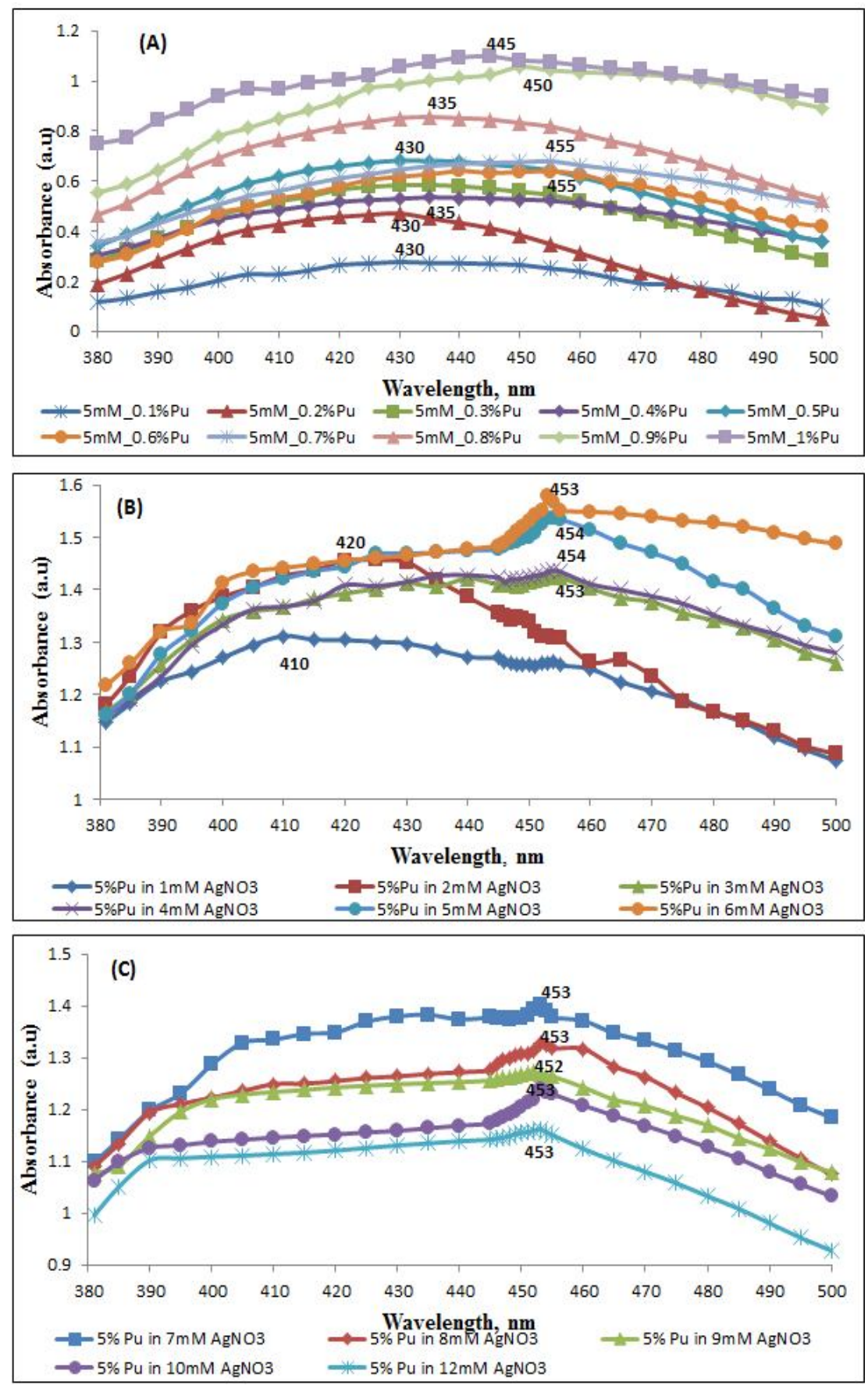

Fig. 2: UV-Visible Surface Plasmon Resonance Spectrum (SPR) of Pullulan Mediated Silver Nanoparticles (Pu-AgNPs): (A) fixed (5 mM) AgNO ${ }_{3}$, varying $(0.1-1.0 \% \mathrm{w} / \mathrm{v})$ Pullulan; (B) fixed (5\% w/v) Pullulan, varying $(1 \mathrm{mM}-6 \mathrm{mM}) \mathrm{AgNO}_{3}$; (C) fixed $(5 \% \mathrm{w} / \mathrm{v})$ Pullulan, varying $(7 \mathrm{mM}-10 \mathrm{mM}, 12 \mathrm{mM})\left(\lambda_{\max }\right.$ indicated on each curve). 


\section{Effect of Pullulan Biopolymer on AgNPs synthesis}

The effect of the reducing/stabilizing agent (Pullulan) on the AgNPs formation is illustrated by recording the UV-VIS spectra for an increasing Pullulan concentration $(0.1-1.0 \% \mathrm{w} / \mathrm{v})$ in Fig. 2 (A). Results shows that ssubstantial increase in SPR bands and intense (430-455 $\mathrm{nm}$ ) wavelength maxima were observed with increasing addition of pullulan into the fixed $(5 \mathrm{mM})$ silver nitrate solution. Pandey et al., (2012) conducted similar experimentation with increasing concentration of Guar Gum (GG) from $1.2 \%$ to $3.5 \%$ and found that higher concentration of GG enhanced the stabilization of synthesized AgNPs. The present study made clear that increasing pullulan concentration plays a significant role in the formation and stabilization of the AgNPs.

\section{Effect of $\mathrm{AgNO}_{3}$ concentration on AgNPs synthesis}

To study the effect of silver nitrate on Pu-AgNPs synthesis, different $(1-10 \mathrm{mM}$ and $12 \mathrm{mM})$ concentrations of $\mathrm{AgNO}_{3}$ are mixed into fixed (5\%) pullulan solution and $\mathrm{UV}$-vis spectra were studied. Formed AgNPs absorbed radiation in the visible regions of 410- $455 \mathrm{~nm}$ due to strong SPR transition (Fig. 2 (B) and (C)). The similar trends of peaks were also reported by Bankura et al. (2012); Pandey et al. (2012), P. Kanmani et al. (2013). Substantial increase in the $\lambda_{\max }$ were observed in $1 \mathrm{mM}$ and $2 \mathrm{mM}$ silver nitrate solution, whereas for 3 to 10 and $12 \mathrm{mM}$ solutions, the absorption maxima is around 452-454 nm. With these results, it was clear that the Pullulan concentration played a significant role in the formation and stabilization of the AgNPs, for varied silver nitrate concentrations. By stability, we mean that there was no observable variation in the optical properties of the formed nanoparticle solutions with time. In another study by Bindhu and Umadevi (2013), reports that the increase in concentration of sliver nitrate could induce the broadening and shifting the SPR band from $445 \mathrm{~nm}$ to $458 \mathrm{~nm}$.

\section{Influence of reaction Time on AgNPs synthesis}

The formation of Pullulan mediated Silver nanoparticles have also been influenced by factors such as Temperature, Time, $\mathrm{pH}$, dielectric properties, and size and shape of particles determine the absorbance and position of SPR bands (Gan et al., 2012; Kanmani et al., 2013). In the present study, Pullulan mediated Silver nanoparticles (Pu-AgNPs) synthesis was evaluated at different reaction times and SPR bands were studied using UV-vis spectroscopy. Fig. 3 (A) shows the UV-vis spectra of silver nanoparticles at different reaction time of 5, 10, 15, 20, 25, 30, 35, 40 and $45 \mathrm{~min}$ and absorbance increases with respect to time. The intensity (absorbance) of the SPR peaks increased as the reaction time increased, which indicated the increased concentration of the silver nanoparticles. Figures 3 (B) and 3 (C) indicates the (linearized) steady increase of maxima of absorbance and wavelengths, further confirms the dependency of time parameter on the silver nanoparticle synthesis in the visible region of spectrum.
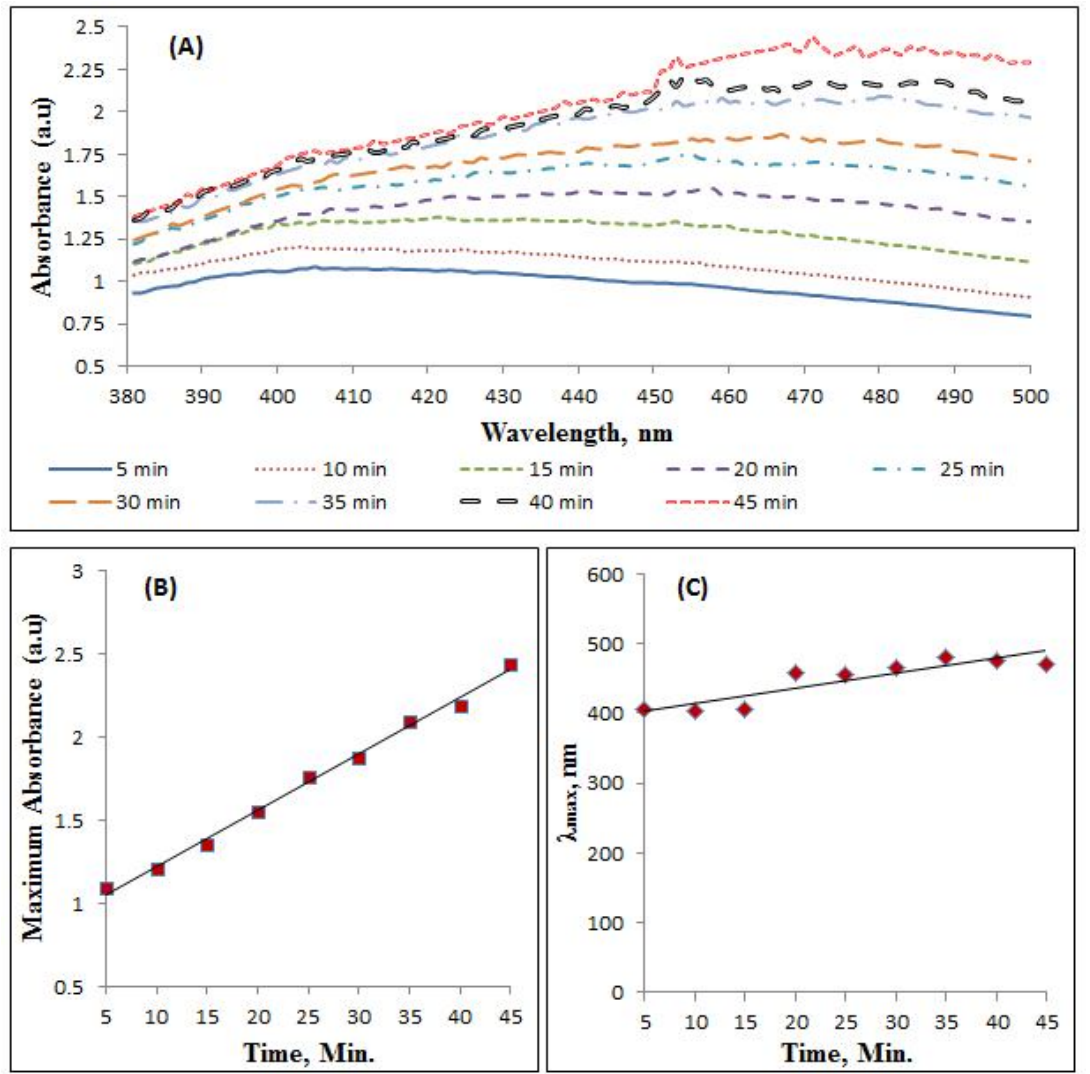

Fig. 3: UV-Visible Surface Plasmon Resonance Spectrum (SPR) of Pullulan Mediated Silver Nanoparticles (Pu-AgNPs) (A) as a function of time, for 9\% Pullulan and $5 \mathrm{mM}$ Silver Nitrate; (B) Maximum absorbance as function of Time (for A figure data); (C) Maximum wavelength $\left(\lambda_{\max }\right)$ as function of Time (for A figure data). 


\section{Influence of pH on AgNPs synthesis}

To study the effect of $\mathrm{pH}$ on synthesis of Silver nanoparticles, the fixed concentrations of Pullulan (5\%) and $\mathrm{AgNO}_{3}(9 \mathrm{mM})$, were stirre for complete dissolution and agitated under sonication. Ultrasound radiation was carried out with ultrasonic processor tip immersed directly into reaction solution. The operating condition was at $15 \mathrm{sec}$ pulse $\mathrm{ON}$ and $15 \mathrm{sec}$ pulse OFF time ampiltude of $70 \%$ at $25{ }^{\circ} \mathrm{C}$ for varied time and $\mathrm{pH}$. The mixture was prepared and observed at two different pH (@ 7.0 and 9.2 for the time of $0,10,20$ and 30 minutes under sonication and this was performed by keeping reaction mixture in ice bucket to reduce the heat effect due to sonication. Figure 4 (A) and (B) indicates the UV-Vis spectrophotometeric observations of absorbance vs wavelength profiles after the Pullulan mediated silver nanoparticles ( $\mathrm{Pu}-\mathrm{AgNPs})$, for the variations in the $\mathrm{pH}$ @ 7.0. and pH@9.2 for the time 0, 10, 20 and $30 \mathrm{~min}$ (in both cases). These spcectra anlysis indicates that the highest peak, $\lambda_{\max }$, has shifted to right with the increase in time, for the both $\mathrm{pH}$. Figure 5 compares the peaks of formed silver nanoparticles, in the case of varied $\mathrm{pH}$ (fixed time) and shows the similar trend in the peak appearance. This indicates that any change in $\mathrm{pH}$, would shift the absorption maxima and confirms the presence of nanoparticles.
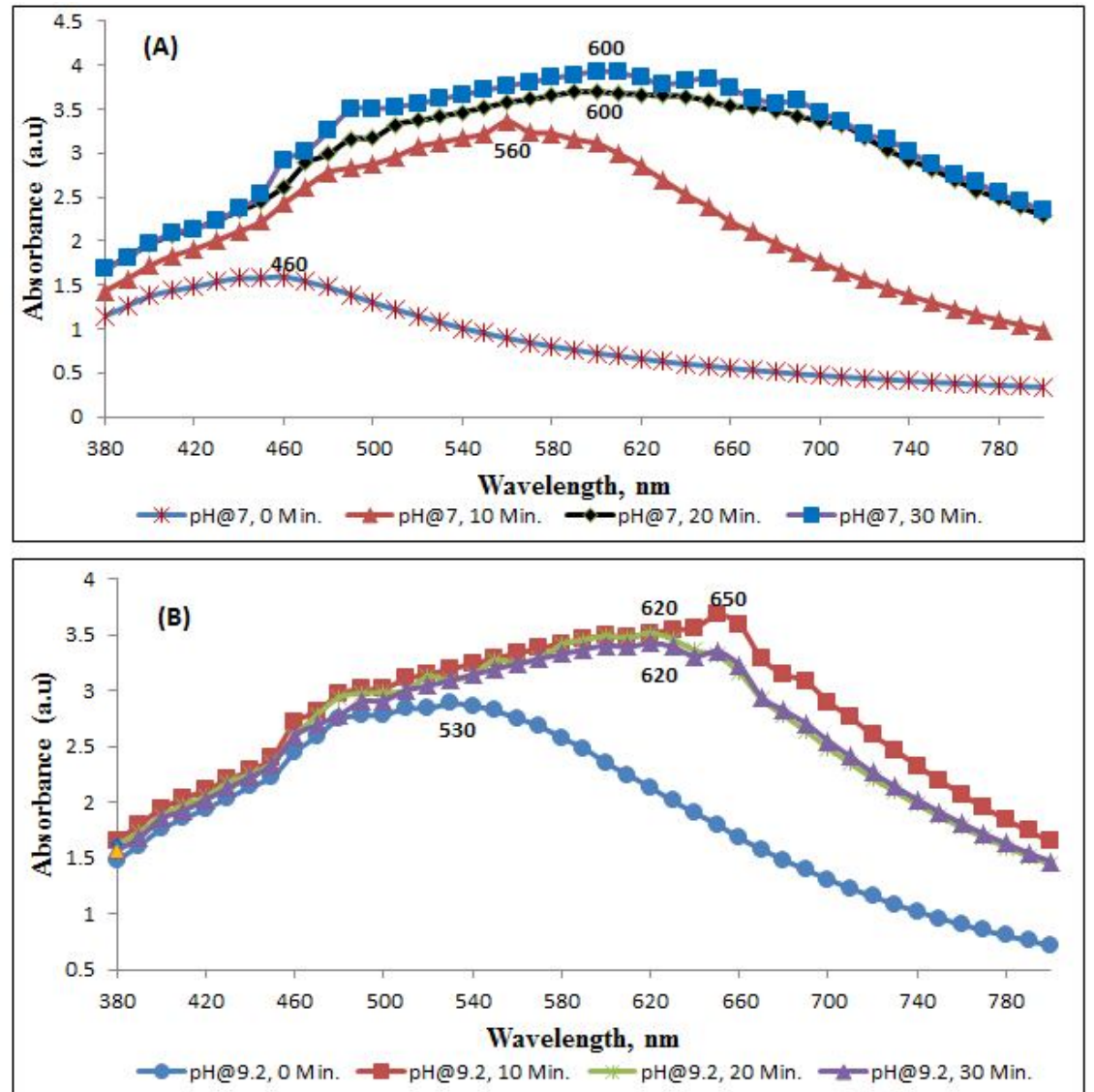

Fig. 4: UV-Visible Surface Plasmon Resonance Spectrum (SPR) of Pullulan Mediated Silver Nanoparticles (Pu-AgNPs) as a function of (A) fixed pH@ @.0; (B) fixed pH@9.2 with variation in time $\left(0,10,20,30 \mathrm{Min}\right.$.) for 5\%Pullulan concentration and $9 \mathrm{mM}$ Silver Nitrate. $\left(\lambda_{\max }\right.$ indicated on each curve).
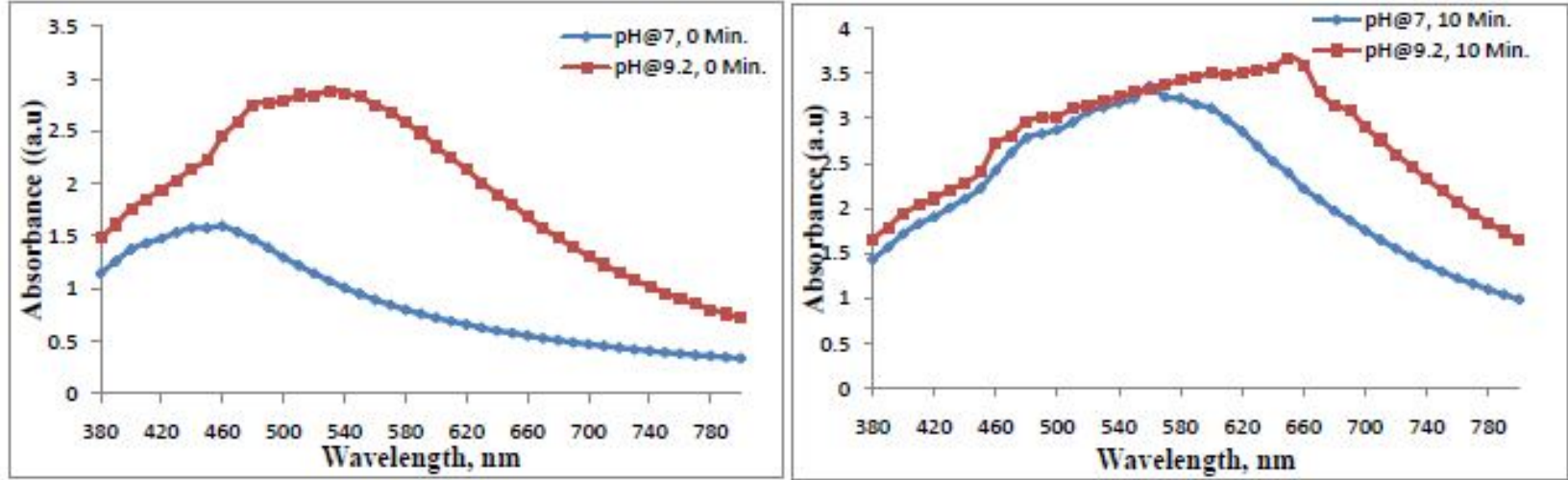

Fig. 5:.. 

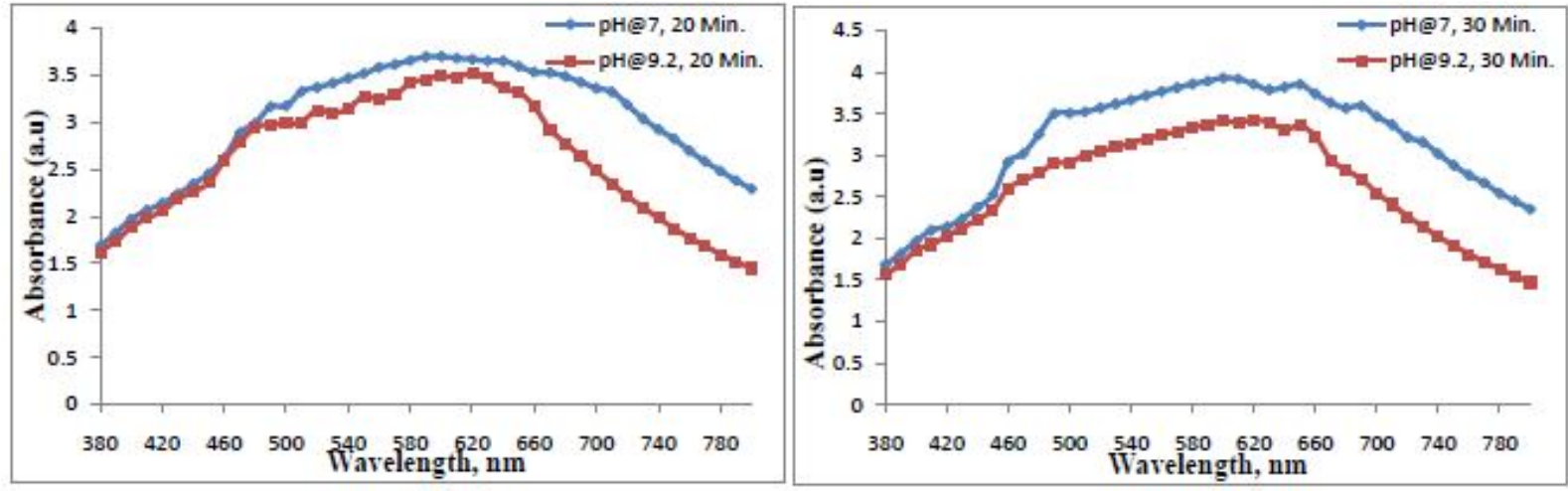

Fig. 5: Comparison of UV-Visible SPR Spectra of Pu-AgNPs as a function of varied pH and time for the data of Fig. 4 (A) and (B).
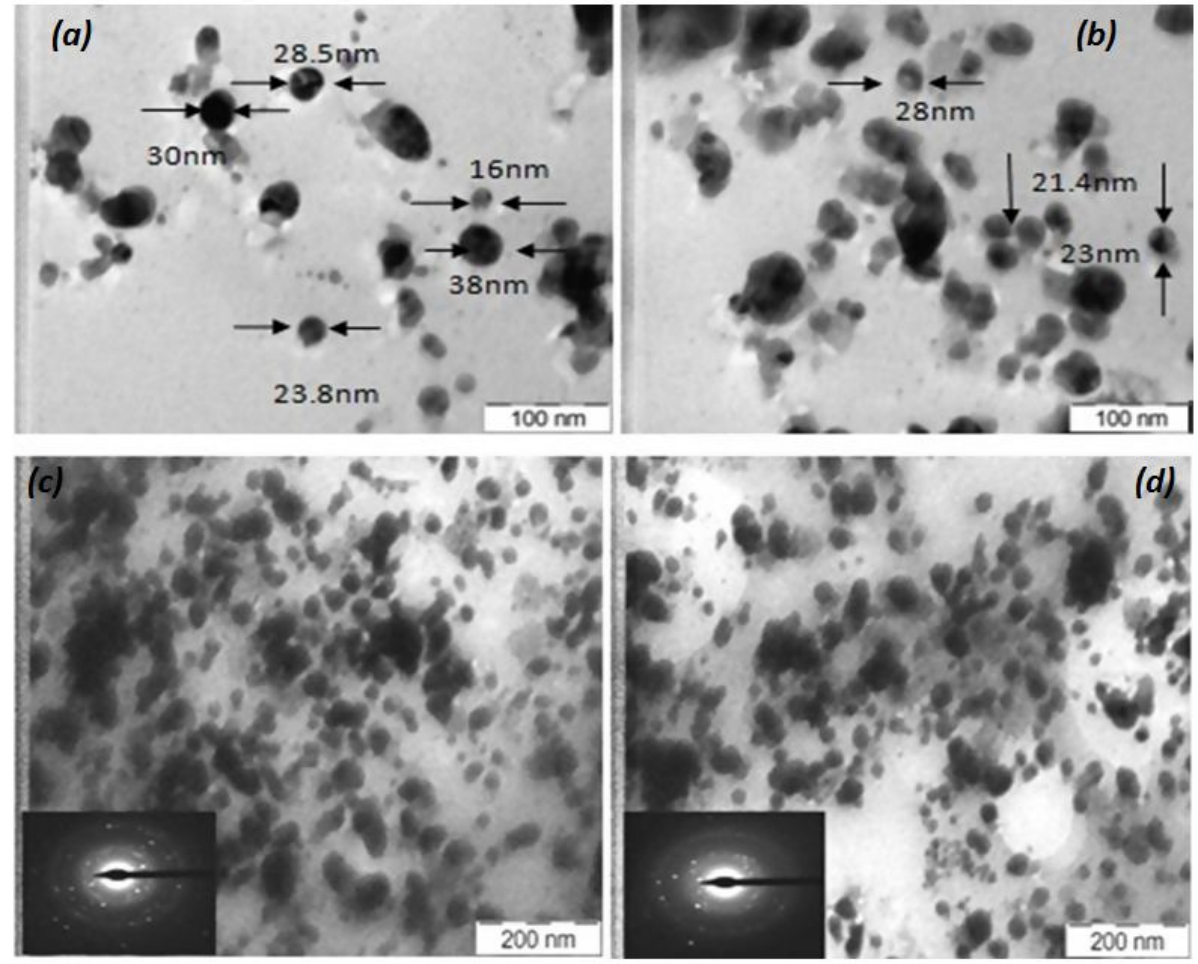

Fig. 6: TEM micrograph of size indicated pullulan reduced AgNPs for $5 \mathrm{~m} \mathrm{M} \mathrm{AgNO}$ and $9 \%(w / v)$ pullulan: $(a),(b)$ the scale bar corresponds to $100 \mathrm{~nm} ;(c),(d)$ the scale corresponds to $200 \mathrm{~nm}$ (inset: SAED pattern).

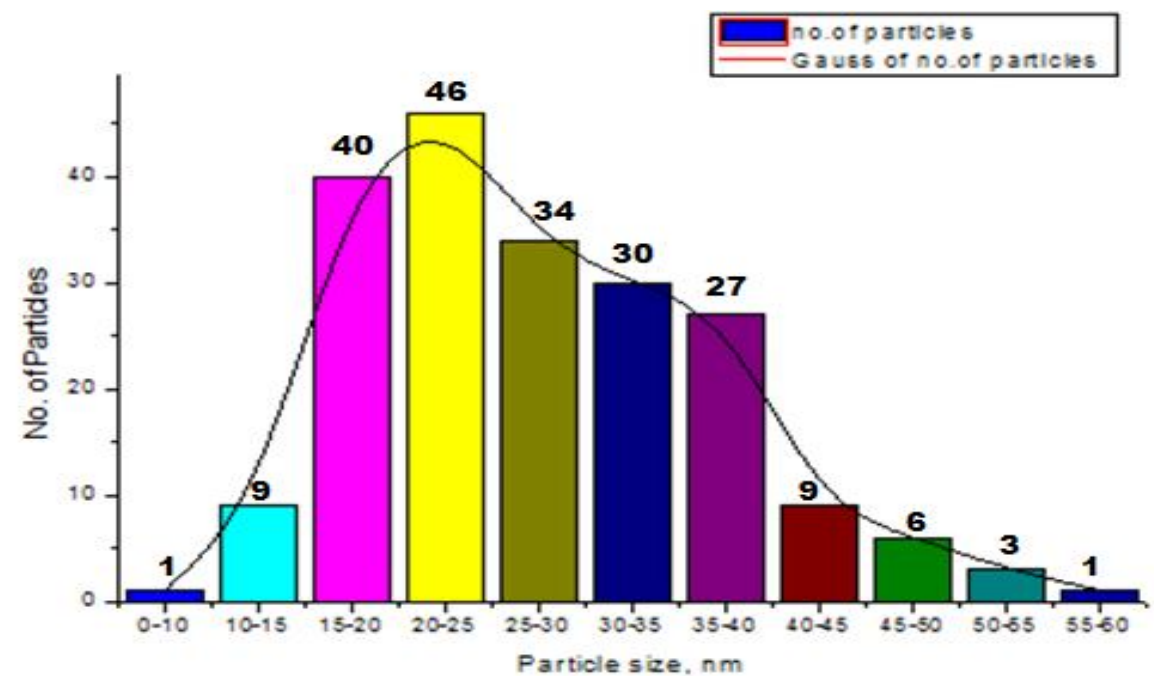

Fig. 7: Histogram of particle size (gauss) distribution curve for synthesized pullulan reduced AgNPs from TEM results. 


\section{Characterization of Pu-AgNPs TEM measurements}

Transmission Electron Microscopic observations were made for synthesized pullulan-mediated AgNPs (Fig. $6(a),(b)$ ). Results show the AgNPs with spherical and smaller particle structures in which individual spherical and oval-shaped AgNPs with an average diameter of 10- $55 \mathrm{~nm}$ were capped by pullulan molecules (Fig. $6(c),(d)$ ). A study of P. Kanmani et al. (2013) indicated that these Pullulan-stabilized AgNPs were having rod and hexagonal shapes, with particle size of 2- $40 \mathrm{~nm}$. In contrast, dextran-stabilized AgNPs are spherical in shape with a particle size of 5-1- nm (Bankura et al. 2012). Figure 7 shows the histogram indicating the (guass) distribution diagram of number of nanoparticles against particle size range. From this figure, it is evident that the major numbers of formed $\mathrm{Pu}-\mathrm{AgNPs}$ are in the particle range of $15-40 \mathrm{~nm}$.

\section{FTIR Analysis}

The FTIR spectra of synthesized Pullulan-stabilized AgNPs were compared with standard 5\% (w/v) Pullulan to analyze the possible functional groups of pullulan responsible for reduction and stabilization of the AgNPs. From the FTIR results, the PuAgNPs have shown characteristic peaks with wave number range from $3371 \mathrm{~cm}^{-1}$ to $1021 \mathrm{~cm}^{-1}$. Broad and strong absorption peaks were observed between $3370-3260 \mathrm{~cm}^{-1}$, indicating the stretching vibration of the hydroxyl groups $(\mathrm{O}-\mathrm{H})$. Another intense absorption peak between $1638 \mathrm{~cm}^{-1}$ to $1635 \mathrm{~cm}^{-1}$, indicated the presence of the carbonyl $(\mathrm{C}=\mathrm{O})$ and $\mathrm{C}=\mathrm{C}$ stretching frequencies. The other peaks in the range between $1160 \mathrm{~cm}^{-1}$ to $1000 \mathrm{~cm}^{-1}$ may be due to vibration of the $\mathrm{O}-\mathrm{H}$ stretching (Fig. 8). Wave numbers in all peaks observed in the FTIR spectra of pullulan-stabilized AgNPs differed from the FTIR spectrum results for pure pullulan. These indications confirm the good interaction of silver with the pullulan functional groups.

From the literature, O-H group of polymer was found efficient coordination ability with silver ions (Pandey et al.2012). A comparison (in Table 1) of AgNPs synthesis from literature and this study with standard pullulan is mentioned as peaks location in wave numbers against vibration modes. Table 2 compares the absorption peaks (in terms of wave numbers) from FTIR analyses (spectra not shown here) for the various combinations of $\mathrm{Pu}$ AgNPs.

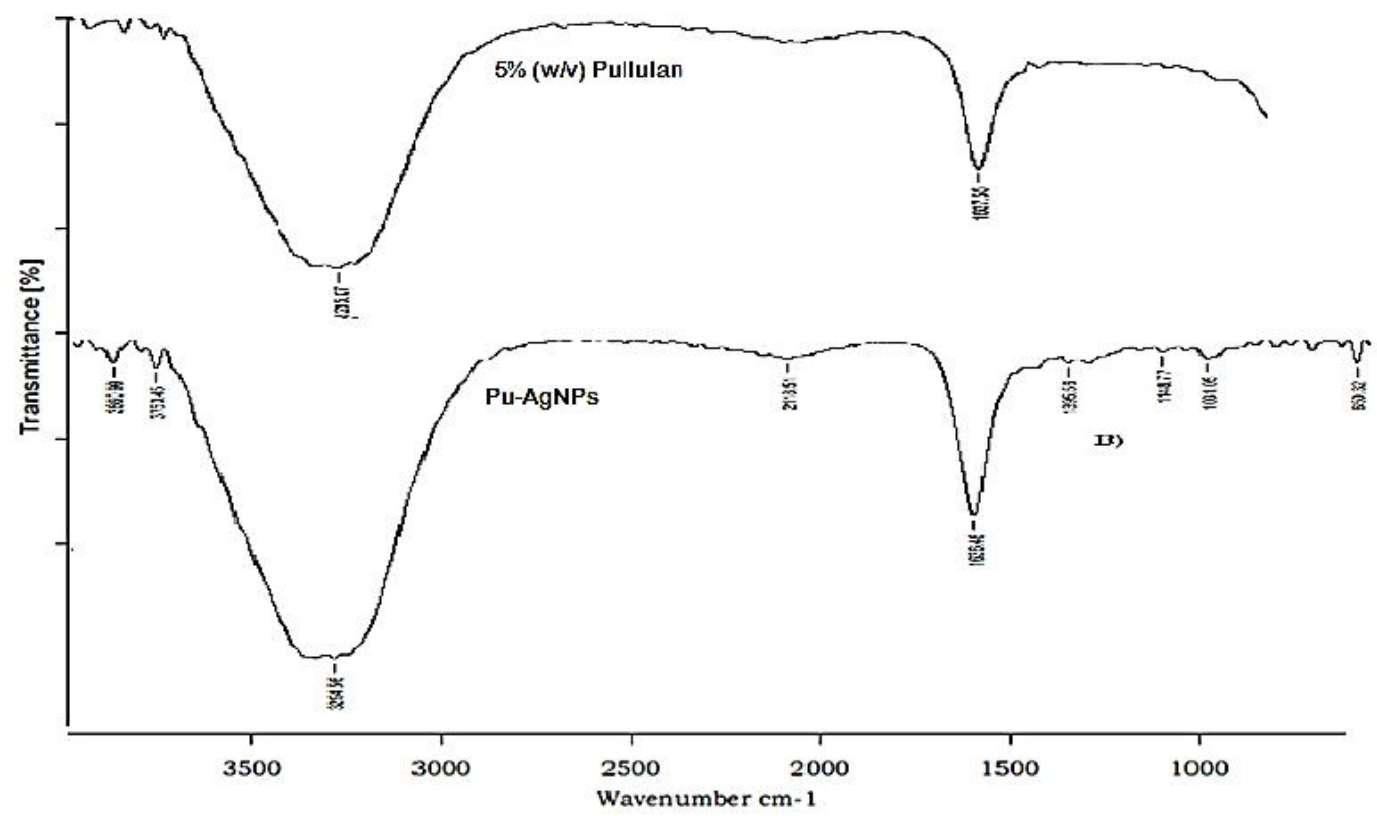

Fig. 8: FTIR spectra of 5\% (w/v) Pullulan (top) and synthesized Pu-AgNPs.

Table 1: Comparison of vibration modes with respect to standard wave numbers.

\begin{tabular}{|c|c|c|c|c|c|c|}
\hline \multirow{3}{*}{$\begin{array}{c}\text { Vibration } \\
\text { Modes } \\
\text { (Functional } \\
\text { Group) }\end{array}$} & \multicolumn{6}{|c|}{ Peak location (Wave number) in $\mathrm{cm}^{-1}$} \\
\hline & \multicolumn{5}{|c|}{ AgNPs synthesis from Literature } & \multirow{2}{*}{$\begin{array}{c}\text { Pullulan mediated } \\
\text { AgNPs } \\
\text { (in this study) }\end{array}$} \\
\hline & Standard & P. Kanmani, 2013 & Mazumder S, 2013 & Amany A et al, 2012 & B.R. Kumar, 2014 & \\
\hline $\mathrm{O}-\mathrm{H} \& \mathrm{~N}-\mathrm{H}$ & $3200-3645$ & 3345 & 3326.56 & 3423 & 3304 & $3259.92-3371.29$ \\
\hline $\mathrm{C}-\mathrm{H}$ & $2700-3100$ & 2914 & $2873.45,2953.85$ & -- & 2928 & -- \\
\hline $\mathrm{C}=\mathrm{O} \& \mathrm{C}=\mathrm{C}$ & $1000-1900$ & 1649 & $1413.61,1600.76$ & $1412,1605,1638$ & 1639 & $1635.62-1638.48$ \\
\hline $\mathrm{C}-\mathrm{O}-\mathrm{C}$ & $1000-1300$ & 1025 & $1017.27,1070.72,1147.82$ & $1032,1100,1230$ & -- & $1020.95-1154.26$ \\
\hline $\mathrm{C} \equiv \mathrm{C}$ & $2040-2260$ & -- & -- & -- & -- & $2088.08-2164.66$ \\
\hline
\end{tabular}


Table 2: Comparison of wave numbers observed in FTIR spectra for the different combinations in Pu-AgNPs synthesis.

\begin{tabular}{cccccc}
\hline Vibration modes & \multicolumn{5}{c}{ Peak location wave number, $\mathbf{c m}^{-1}$} \\
\cline { 2 - 6 } (Functional Group) & Standard & A & B & C & D \\
\hline O-H,N-H & $3200-3550$ & $3294.56-3371.31$ & 3275.2 & 3344.18 & $3305.29-3371.29$ \\
C $\equiv$ C & $2100-2250$ & $2118.51-2128.75$ & 2120.19 & 2068.06 & $2116.31-2124.35$ \\
C=O & $1630-1695$ & $1636.01-1636.48$ & 1637.2 & 1637.15 & $1636.63-1638.48$ \\
C-O-C & $970-1250$ & $1020.95-1149.89$ & $1023.52,1152.38$ & $1025.02,1153.96$ & $1022.73-1154.26$ \\
C-H & $600-700$ & $650.32-676.05$ & 654.99 & 653.54 & $641.87-664.06$ \\
\hline
\end{tabular}

A: Pu-AgNPs synthesized using $9 \mathrm{mM}$ silver nitrate and 3,5,7,9\% Pullulan for 15 minutes reaction time. B: Pu-AgNPs synthesized using $5 \mathrm{mM}$ silver nitrate and $9 \%$ Pullulan for 40 minutes reaction time. C: Pu-AgNPs synthesized using $10 \mathrm{mM}$ silver nitrate and $9 \%$ Pullulan for 20 minutes reaction time. D: Pu-AgNPs synthesized using $9 \mathrm{mM}$ silver nitrate and $10 \%$ Pullulan for $5.5,7.5,10.5 \mathrm{pH}$.

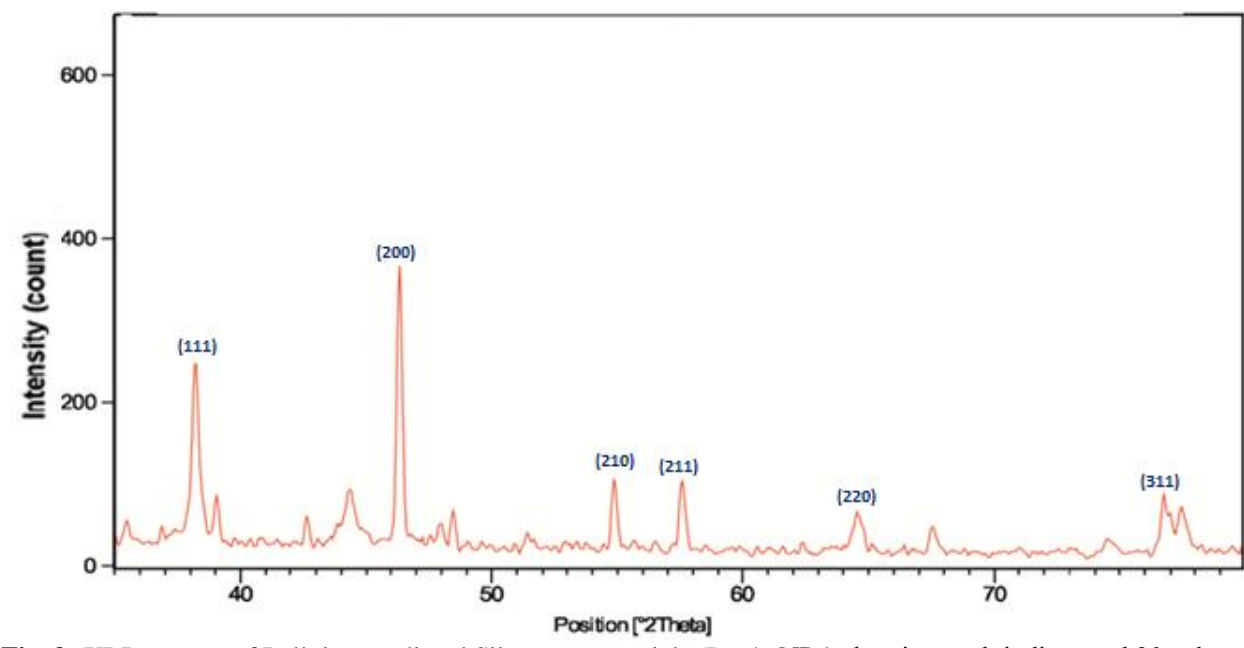

Fig. 9: XRD pattern of Pullulan-mediated Silver nano particle (Pu-AgNPs) showing peak indices and $2 \theta$ values.

\section{XRD analysis}

The synthesized Pu-AgNPs were analysed by X-ray Diffraction (XRD) scanning on Philips PAN instrument operated with $\mathrm{Cu}-\mathrm{K} \alpha(\lambda=1.5406 \AA)$ radiation at voltage of $30 \mathrm{kV}$ and current of $20 \mathrm{MA}$ with scan rate of $0.030 / \mathrm{s}$ according to the description of Wang and Zhou (2000). The diffraction intensities were recorded from $35^{\circ}$ to $79.93^{\circ}$, in $2 \theta$ angles and compared with the standard JCPDS silver file No. 04-0783 (Fig. 9). Six peaks at $2 \theta$ values of $38.174,46.5,54.8576,57.524,64.501$ and $77.045^{\circ}$ corresponding to (111), (200), (210), (211), (220) and (311) planes of Silver confirms / indicates that the resultant particles are (FCC) Silver Nanoparticles. No spurious diffractions due to crystallographic impurities are found. All the reflections correspond to pure silver metal with face centred cubic symmetry. The high intense peak for FCC materials is (200) reflection, which is observed in the sample. The intensity of peaks reflected the high degree of crystallinity of the silver nanoparticles. However, the diffraction peaks are broad which indicating that the crystallite size is small.

The XRD shows that silver nanoparticles formed are crystalline. The appearance of this sharp peak could have resulted from crystallization of the reducing and stabilizing agent in the AgNPs. Similar results were observed by Kanmani et al. (2013) with pullulan and by Bankura et al. (2012)and Roopan et al. (2013) for AgNPs synthesized with dextran and a coir waste extract. The sizes of the formed $\mathrm{Pu}-\mathrm{AgNPs}$ estimated from the Debye-Scherrer's formula and the calculated nanoparticle size (in $\mathrm{nm}$ ) also confirm the results obtained in average particle diameters from TEM studies.

\section{Application of Pu-AgNPs as Bactericidal agents}

Silver nanoparticles have been shown to have effective antibacterial activity against a range of disease-causing bacteria. The antibacterial activity of the Pu-AgNPs was investigated against four, two gram-positive and two gram negative bacterial pathogens using the agar well diffusion method. The clear inhibition zones (Fig. 10) were observed after $24 \mathrm{~h}$ incubation at $37^{0} \mathrm{C}$.It was apparent that all bacterial pathogens were highly inhibited in aldose-dependent manner. Increases in the inhibition zones were observed with an increase in the amount of AgNPs added. The results for the inhibitions zone and their average values are shown in Fig. 11. Among the bacterial pathogens, grampositive Bacillus subtilis have shown more strong inhibitory (+++) effect to AgNPs followed by Staphylococcus aureus and gramnegative Serretia marescenes. The other gram-negative Escherichia coli were less susceptible to the AgNPs. Similar results in antimicrobial activity studies were also reported by Sondi et al., (2004); Morones et al., (2005); Kim et al., (2007); Feng et al., (2008); Birla et al., (2009); Bankura et al.(2012); Priyadarshini et al. (2013). Based on these results, it can be concluded that pullulan mediated silver nanoparticles had significant antibacterial action on a large variety of bacteria ranged from Gram-positive to Gram-negative ones. 


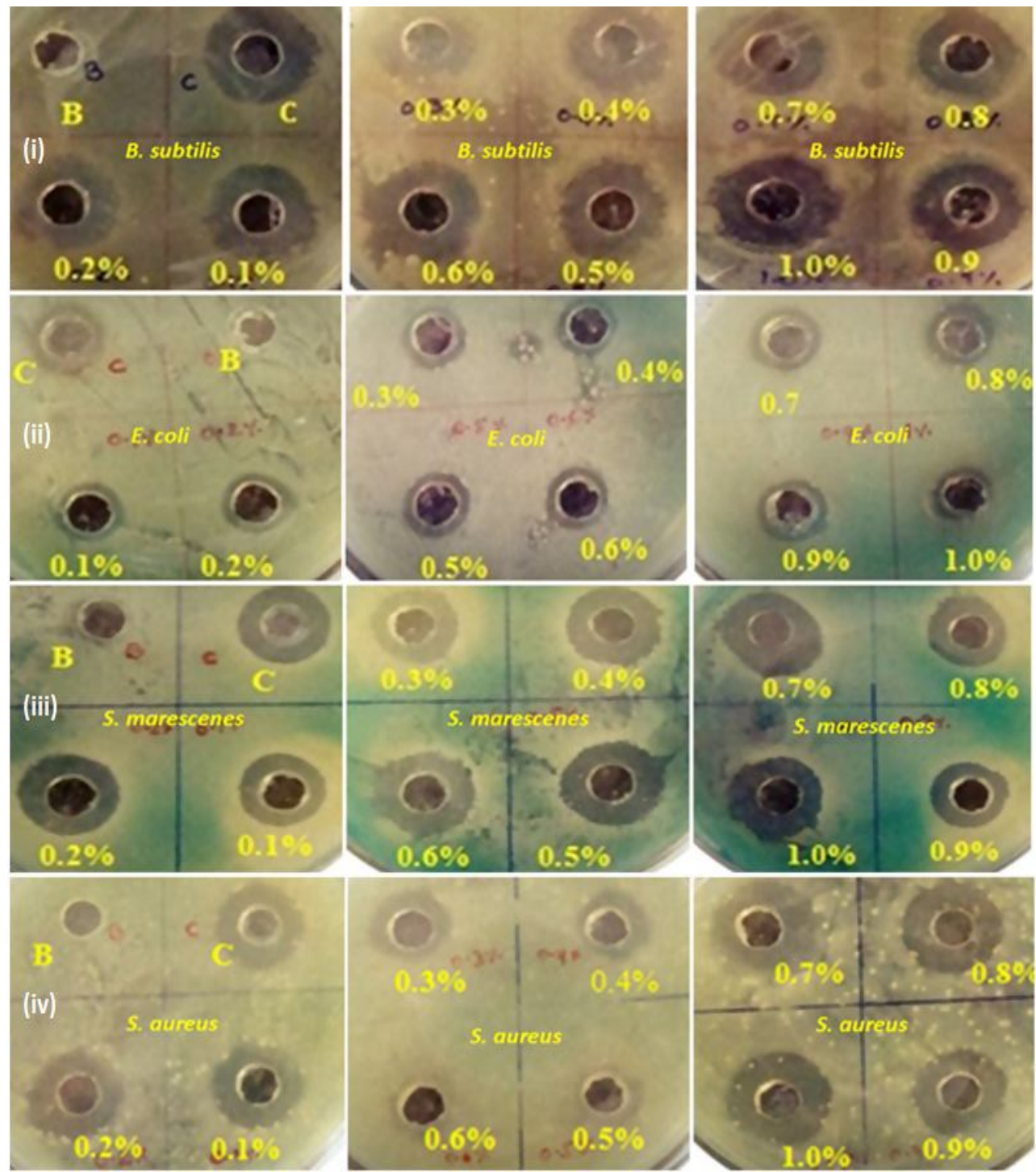

Fig. 10: Antibacterial activity of different concentrations (fixed $5 \mathrm{mM} \mathrm{AgNO}_{3}+0.1$ to $1.0 \%$ (w/v) Pullulan) of Pu-AgNPs against four bacterial pathogens (i) $B$. subtilis, (ii) E.coli, (iii) S.marescenes, (iv) S.aureus in agar medium after $24 \mathrm{~h}$ of incubation at $37^{\circ} \mathrm{C}$. B: (sterile) Distilled water, C: $5 \mathrm{mM} \mathrm{AgNO} \mathrm{A}_{3}$ (only).

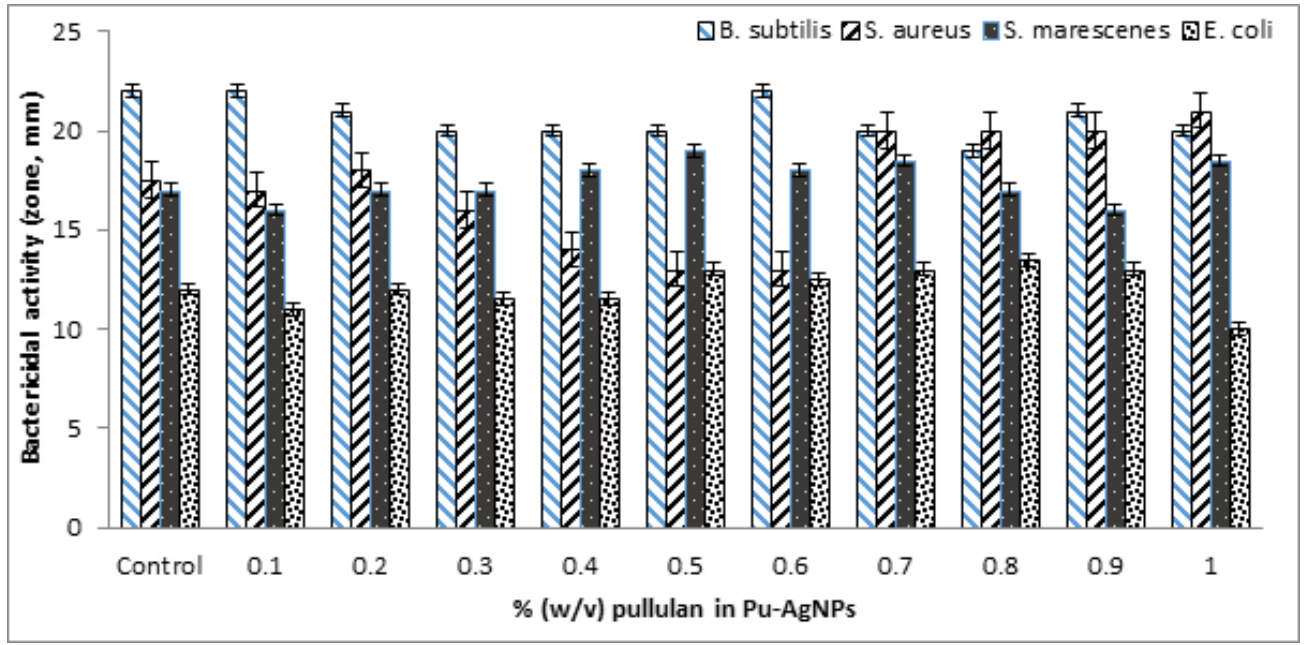

Fig. 11: Average diameter inhibition zones of four bacterial strains against increasing $(0.1-1.0 \% \mathrm{w} / \mathrm{v})$ concentration of Pullulan in Pullulan-stabilized silver nanoparticles. 


\section{CONCLUSION}

In conclusion, we introduce a simple, safe, energy saving, fast, and economical chemical reduction method to synthesize a biopolymer mediated Silver nanoparticles (PuAgNPs). The synthesized Silver nanoparticles are in spherical shape with particle sizes between $10-55 \mathrm{~nm}$. Their characterizations have been successfully done using UV-VIS spectroscopy, XRD, TEM and FTIR spectroscopic techniques. Then pullulan-reduced AgNPs' potent antibacterial activities were analyzed using the agar well diffusion for the pathogenssuch as E. coli, S. aureus, B. subtilis and $S$. marescenes. Results of antimicrobial activity revealed that the all bacterial pathogens were inhibited in a dosedependent manner. The pathogen B. subtilis was more susceptible to AgNPs followed by Staphylococcus aureus and gram- negative Serratia marescenes. These experimental results suggest that pullulan-reduced AgNPs can be used as potent antimicrobial agent for various biomedical applications.

Conflicts of Interests: The authors declare that they have no conflict of interest on publication of this article.

\section{ACKNOWLEDGEMENTS}

First and corresponding author thank the management of K L University, Vaddeswaram and Acharya Nagarjuna University, Guntur for their support.

\section{REFERENCES}

Amany A, El-Kheshen1, Sanaa F. Gad El-Rab. Effect of reducing and protecting agents on size of silver nanoparticles and their anti-bacterial activity, Scholars Research Library Der Pharma Chemical, 2012;4 (1):53-65.

Bankura K P, Maity D, Mollick M M R, Mondal D, Bhowmick, B, Bain M. K. Synthesis, characterization and antimicrobial activity of dextran stabilized silver nanoparticles in aqueous medium. Carb Poly, 2012;89: 1159-1165.

Bindhu MR, Umadevi, M. Synthesis of monodispersed silver nanoparticlesusing Hibiscus cannabinus leaf extract and its antimicrobial activity. Spectrochemica Acta part A: Mol BiomolSpec, 2013;101: 184190.

Kumar B, Smita K, Cumbal L, Debut A, Pathak RN. Sonochemical Synthesis of Silver Nanoparticles Using Starch: acomparison, BioinorgChemAppl, 2014;2014:8.

Birla S S, Tiwari VV, Gade A K, Ingle A P, Yadav AP, Rai M K. Fabrication of silver nanoparticles by Phomaglomerata and its combined effect against Escherichia coli, Pseudomonas aeruginosa and Staphylococcus aureus. Lett ApplMicrobiol, 2009;48: 173-179.

Burda.C,Chen.X, Narayanan R, El-Sayed MA.Chemistry and Properties of Nanocrystals of different shapes, Chemical Reviews,2005; 105(4):1025-1102.

Coseri S, Spatareanu A, Sacarescu L, Rimbu C, Suteu D, Spirk S, Harabagiu V. Green synthesis of the silver nanoparticles mediated by pullulan and 6-carboxypullulan, Carbohydrate Polymers, 2015; 116: 9-17.

Feng.Q, Wu.J, Chen.GQ, Cui. FZ, Kim.TN, Kim.JO.A mechanistic study of the antibacterial effect of silver ions on Escherichia coli and Staphylococcus aureus,Journal. Biomedical Materials Research, 2008;52: 662-668.

Gan PP, Ng SH., Huang Y, \&Yau Li SF. Green synthesis of gold nanoparticles using palm oil mill effluent (POME): A low-cost and eco-friendly viable approach. Bioresource Technology, 2012;113: 132135.
GuariY, Thieuleux C, Mehdi A., Reye C, Corriu RJP., GomezGallardo S. In situ formation of gold nanoparticles within thiol functionalized HMS-C-16 and SBA-15 type materials via an organometallic two-step approach, Chemistry of Materials, 2003; 15: 2017-2024.

Hebeish A, Hashem M, Abd El-Hady MM, Sharaf S. Developmentof CMC hydrogels loaded with silver nano-particles for medical applications, Carbohydrate Polymers, 2013;92: 407-413.

Hernane S Barud, Thais Regiani, Rodrigo F, Marques C, Wilton R Lustri, YounesMessaddeq, Sidney JLR. Antimicrobial Bacterial Cellulose-silver nanoparticles composite membranes, Journal of Nanomaterials, 2011; 2011:1-8.

Kalishwaralal K, BarathManiKanth S, Ram Kumar Pandian S, Deepak V,Gurunathan S. Silver nanoparticles impede the biofilm formation by Pseudomonas aeruginosa and Staphylococcus epidermidis. Colloids and Surfaces B: Biointerfaces, 2010;79: 340-344.

Kaya A, Du X, Liu Z, Lu JW, Morris J R, Glasser WG. Surfaceplasmon resonance studies of pullulan and pullulan cinnamate adsorption ontocellulose. Biomacromolecules, 2008;10: 2451-2459.

KimJ, Kuk E, Yu K, Kim JH, ParkSJ, Lee HJ, Kim SH, Park YK, ParkYH, HwangC-Y, Kim YK, Lee YS, JeongDH, ChoMH. Antimicrobial effects of silver nanoparticles, Nanomedicine, 2003; 3:95101.

KoraAJ, ArunachalamJ.Assessment of antibacterial activity of silvernanoparticles on Pseudomonas aeruginosa and its mechanism of action, WorldJournal of Microbiology and Biotechnology, 2011; 27: 1209-1216.

Liz-Marzan LM. Tailoring Surface Plasmons through the Morphology and Assembly of Metal Nanoparticles, Langmuir, 2006;22(1): 32-41.

Mariam J, Dongre PM, Kothari DC. Study of interaction of silver nanoparticles with bovine serum albumin using fluorescence spectroscopy, Journal of Fluorescence, 2011;21(6):2193-2199.

Mazumder S, Pereira J, Edgar JK, Davis MR. Synthesis and characterization of drug-polysaccharide nanoparticles for oral drug delivery applications, 2013; ACS 245th National Meeting, New Orleans, USA.

Morones JR, Elechiguerra JL, Camacho A, Holt K, Kouri JB, Ram'irez JT,YacamamMJ. The bactericidal effect of silver nanoparticles,Nanotechnology, 2005; 16: 2346-2353.

Moura MRde, Mattoso LHC, Zucolotto V. Development of cellulose based bactericidal nanocomposites containing silver nanoparticles and their useas active food packaging, Journal Food Engineering, 2012; 109: 520-524.

Narayanan KB, Sakthivel N. Heterogeneous catalytic reduction of anthropogenic pollutant, 4-nitrophenolby silver-bionanocomposite using Cylindrocladium floridanum, Bioresource Technology, 2011;102: 10737-10740.

PandeyS, Goswami GK, Nanda KK. Green synthesis of biopolymer-silver nanoparticle nanocomposite: An optical sensor for ammonia detection. International Journal of Biological Macromolecules, 2012; 51: 583-589.

Paulraj Kanmani, Seung Taik Lim. Synthesis and characterization of pullulan-mediated silver nanoparticles and its antimicrobial activities, carbohydrate polymers, 2013;97: 421-428.

Paulraj Kanmani, Jong-WhanRhim. Physicochemical properties of gelatin/silver nanoparticle antimicrobial composite films, Food Chemistry, 2014;148: 162-169.

Priyadarshini S, Gopinath V, Meera Priyadharsshini N, MubarakAli D, and Velusamy P. Synthesis of anisotropic silver nanoparticles using novel strain, Bacillusflexus and its biomedical application, Colloids and surfaces. B: Bio interfaces, 2013;102: 232-237.

RaveendranP, Fu J,Wallen SL.Completely green synthesis and stabilization of metal nanoparticles. Journal of the American Chemical Society, 2003;125:13940-13941.

Roopan SM, Rohit Madhumitha G, Abdul Rahumanb A, Kamaraj C, BharathiA, Surendra TV. Low-cost and eco-friendly phytosynthesis of silvernanoparticles using Cocos nucifera coir extract 
and its larvicidal activity, Industrial Crops and Products, 2013;43: 631635 .

Shilpa Sharma, Pallab Sanpui, Arun Chattopadhyay, Siddhartha Sankar Ghosh. Fabrication of antibacterial silver nanoparticle-sodium alginate-chitosancomposite films, RSC Advances, 2012; 2: 5837-5843.

Singaravelu Vivekanandhan, Laura Christensen, Manjusri Misra, Amar Kumar Mohanty. Green Process for Impregnation of Silver Nanoparticles into Microcrystalline Cellulose and Their Antimicrobial Bionanocomposite Films, Journal of Biomaterials and Nanobiotechnology, 2012; 3: 371-376.

Spatareanu A, Bercea M, Budtova T, Harabagiu V, Sacarescu L, Coseri S. Synthesis, characterization and solution behaviour of oxidized Pullulan, Carbohydrate Polymers, 2014;111: 63-71.

Sondi I, Salopek-Sondi. B. Silver nanoparticles as antimicrobial agent: a case study on E. coli as a model for Gram-negative bacteria, Journal of colloidal interface science, 2004; 275: 177-182.

Stiger RM, Gorer S, Craft B, Penner PM. Investigations of electrochemical silver nanocrystal growth on hydrogen-terminated silicon (1 0 0). Langmuir, 1999; 15(3), 790-798.

Wang H, Zhou J. Data smoothing and distortion of X-ray diffraction peaks. II. Application, Journal of Applied Crystallography, 2000;33: 1136-1142
Wei X, Luo M, Li W, Yang L, Liang X, Xu L. Synthesis of silver naanoparticles by solar irradiation of cell-free Bacillus amyloliquefaciens extracts and $\mathrm{AgNO}_{3}$ Bioresource Technology, 2012; 103: 273-278.

Wu J, Zhong F, Li Y, Shoemaker FF, Xia W. Preparation and characterization of pullulan-chitosan and pullulan-carboxymethyl chitosan blended films, Food Hydrocolloids, 2013; 30: 82-91.

Yang G, Lin Q, Wang C, Li J, Wang J, Zhou J, Wang Y, Wang C. Synthesis and characterization of dextran-capped silver nanoparticles with enhanced antibacterial activity, Journal of Nanoscience and Nanotechnology, 2012;12 (5): 3766-3774.

\section{How to cite this article:}

Ganduri VSRK, Mangamuri U, Muvva V, Poda S. PullulanStabilized Silver Nanoparticles - Their Synthesis, Characterization and Application as Bactericidal Agents. J App Pharm Sci, 2016; 6 (07): 027-037. 